International Research Journal of Management, IT \& Social Sciences
Available online at https://sloap.org/journals/index.php/irjmis/
Vol. 6 No. 6, November 2019, pages: 37 42
ISSN: 2395-7492
https://doi.org/10.21744/irjmis.v6n6.754

\title{
Computer Application for Studies of Potential Renewable Energy
} Sources

\author{
Juan Alejandro Martinez Linares ${ }^{\text {a }}$ \\ María Rodríguez Gámez ${ }^{\text {b }}$ \\ Antonio Vázquez Pérez ${ }^{\mathrm{c}}$
}

\section{Article history:}

Received: 09 May 2019

Accepted: 31 July 2019

Published: 27 September 2019

\section{Keywords:}

geographical;

information systems;

renewable energy sources;

renewable energy potentials;

territorial energy ordination;

\begin{abstract}
Computer science's technologies have come to revolutionize the current era, the distributed generation and the introduction of new alternatives in the conception of the energy production, it is a factor that seen from the energy planning it allows to introduce the renewable energy sources (RES) as an element in the development of energetically sustainable territories. The space distribution of the natural resources that the RES generates, it has made necessary to develop advanced systems for the studies at space level. For the Needs of printing an analysis space and territorial of the RES studies, a geographical information system of renewable energy sources of was designed (SIGFRE), using free software, that offers information of the renewable potentials in the territory. This system is a tool that allows an appropriate way to offers information on the place (longitude and latitude) and the potentials (solar, hydric, wind, and biomass) that are generated in them.
\end{abstract}

2395-7492@ Copyright 2019. The Author. This is an open-access article under the CC BY-SA license (https://creativecommons.org/licenses/by-sa/4.0/) All rights reserved.

\section{Author correspondence: \\ Juan Alejandro Martinez Linares, \\ Center for Electroenergetic Research and Testing, \\ Universidad Tecnológica de La Habana, Havana, Cuba. \\ Email address: alej1286@gmail.com}

\section{Introduction}

Currently, websites and Geographic Information Systems (SIG, 2019), are conceived as an application on different fronts, as they are instruments that allow companies and decision-makers to help the real knowledge of the space where relationships occur social and its interaction with the environment. Geographic Information Technologies (Stiglitz, 2012), are considered part of the central core of Geography, since geographers have a prominent role in its development, are part of the main conceptual traditions of the matter, and have a strong professional projection (Chuvieo et al., 2005; Pérez et al., 2016).

${ }^{a}$ Universidad Tecnológica de La Habana, Havana, Cuba

b Universidad Técnica de Manabí, Portoviejo, Ecuador [taliangel270557@gmail.com]

c Universidad Técnica de Manabí, Portoviejo, Ecuador [antoniov5506@ gmail.com] 
The Geographic Information System of Renewable Energy Sources (SIGFRE) in Cuba, is a tool that in energy applications has gone through several scenarios and levels of development, in a first stage it was designed for a municipality in the inventory of communities and settlements that were not electrified (Rodriguez et al., 1998), this technology was transiting for provincial studies, its fundamental application was carried out in the province of Santiago de Cuba (Rodríguez \& Marquez, 1999) and taking into account the results obtained, it was used in the energy planning of said territory (Rodriguez et al., 2000; Ramos et al., 2018). The application of the system has been developed and expanded to new provinces that are incorporated into the database (BD), between 1998 and 2002 it was generalized to the five eastern provinces (Holguín, Granma, Guantanamo, Las Tunas and Santiago de Cuba), mainly for inventories and knowledge of communities without electrification, as well as the study of the type of electrification existing (Rodriguez et al., 2005; Cedeno et al., 2017).

To ensure that the application could be introduced, in such a way that it offered information and that it could also be updated, make reports, print, etc. a variant was developed that in its beginnings was able to manage the potentials in the territory, providing information for the pre-investment stage, being able to perform the macro location based on the inventories of potentials of renewable energy sources (RES) and the elements of the space that influence and relate to achieve the management of the energies in the territory, but this system had to be user friendly and easy to handle.

To meet these expectations, it was essential to go through a stage, in which the requirements that would lay the foundations of the FRE's potentials in the application to be implemented were compiled. Therefore, based on the domain model obtained, and with the objective of establishing the second module as the main element of the SIGFRE, based on determining the functionalities that it will have, in order to guide the development towards obtaining a design that meets the client's required expectations and that can be used throughout the country for territorial energy study and planning during the pre-investment stage as part of the decision-making process in the introduction of the FRE, based on the concepts that the reality of the energy space can be known, which includes the satisfaction of the demand in the population centers of greater consumption.

\section{Materials and Methods}

The base created at the country level was used as a starting point, based on the existing administrative political division. For the design of the base maps to be used, 1: 250000 and 1: 100000 cartography was used. For the potential maps, information was taken from different sources: the solar and wind potential was developed with data published on the SWERA website (Solar and Wind Energy Resource Assessment); the map of hydraulic potential was prepared with the existing cartography up to the level of dams and rivers and alphanumerical information provided by the Hidroenergía company; The biomass potentials for being so diverse worked with different types of information in 1: 100000 cartography for the maps of the country, where the soils occupied by cane, coffee, marabou, rice, forests etc. were inventoried; The biomass for the generation of biogas was obtained with the inventories of the industries that generate considerable amounts in their processes of organic waste, in addition to the inventory of the facilities where concentrates, pigs, poultry, cattle, and goats are located, etc.

Free software was used, downloaded from the internet with the objective that the system that is designed can be multiplied and achieve the expected results in relation to its use and the enrichment of the database of the FRE potentials, as well as of the applications of technologies that take advantage of renewable resources.

\section{Results and Discussions}

\section{Background}

With some frequency, the image of the territory possessed by specialists and some decision-makers in the energy sector does not adjust exactly to geographical reality or to the relationships established therein. The territorial imprint of the implementation of renewable energy sources, as well as the incorporation of economic concepts in their application and use, makes it necessary to reconcile the criteria for intervention, regulation and integration within the energy organization.

Until the moment that SIGFRE is conceived, the extraordinary volume of information that exists on the inventory and the potential of renewable energy sources, are scattered in the profile of the institutions and organizations that have the responsibility to control their development, is for example: that there is a National Group of Photovoltaic Solar 
Energy; another for solar thermal energy; a group for wind energy; for hydraulics; and in the case of bioenergy it is subdivided by types, in addition to others that when they are not directly related to its use, have to do with its use as is the case of the Energy Accumulation Group.

From an institutional point of view, the Electric Union has the Emergency Directorate that, among its functions, serves the development and management of wind farms, existing hydroelectric plants of different powers and photovoltaic power plants connected to the grid; but the windmills that use wind energy are served in part by the Ministry of Agriculture and autonomous photovoltaic systems are served by COPEXTEL. In this way, issues related to the development of renewable sources are dispersed in various state and government institutions.

In this scenario it is difficult to be able to establish an analysis on the energy management that may have an integrative character, where it is possible to evaluate the availability of the different energy sources, to have an idea of which of them is more economical and of better environmental impacts or social, being able to make a decision adjusted to the introduction of the variant that is most profitable and safe for investment. In any case, if an evaluation of this nature is to be carried out, it is necessary to invest time and resources in information, meetings, trips, consultations and other activities that are not always possible to achieve due to space, time and availability of material and economic resources.

The above can be corroborated by the results of the report with the guide of recommendations for the use of renewable energies in rural electrification, presented on July 2002 by the International Technical Cooperation Agency of Japan (JICA), with the cooperation of the Solar Energy Research Center (CIES) and the Center for Priority Program and Project Management (GEPROP), both of the Ministry of Science, Technology and Environment (CITMA) of the Government of Cuba (Shiota et al., 2020; Chilán et al., 2018).

SIGFRE manages to link all the required information in a single place, in order to be able to carry out analyzes and evaluations in an integral manner, on the opportunities for the intervention of each energy source in the development plans of the country and territories. The information can be accessed from anywhere and related to any site in the national territory, with the incorporation of georeferenced graphic attributes, capable of providing a wider spectrum of local information references.

The argument of the tools, languages and technologies to use

Prado version 3.1.7 has been used as a PHP framework, with the aim of making possible the manipulation of each module of the application, in a simple way and with the minimum possible errors, since it is a well-defined conceptual and technological support structure, normally with specific artifacts or software modules, on the basis of which our project can be organized and developed.

PRADO is a PHP framework or component-based programming layer and event programming, for the implementation of Web applications in PHP 5, PRADO (PHP Rapid Application Development Object-oriented) which means in Spanish rapid development of applications with programming oriented to objects in PHP (EcuRed, 2012).

Geoserver is an open-source server written in Java, which allows users to share and edit geospatial data. It has been designed from the beginning to operate under interoperability standards. It is able to publish services from the main data sources using open standards (Geoserver, 2012). Version 2.3.2 has been used as a geospatial data server, that is, a map server and its data, which allows users to consult and edit data throughout the project.

PostgreSQL database is a relational management system (DBMS) oriented to free software objects, published under the BSD license. Like many other projects open source, the development of PostgreSQL is not managed by a single company but is directed by a community of developers and commercial organizations, which work on its development. This community is called the PostgreSQL Global Development Group (PGDG) (PostgreSQL, 2012).

During the design of the project, it was estimated to use the PostgreSQL version 9.1 DBMS, where all the geospatial data with which the system will work will be stored.

PostGIS is a module that adds support of geographical objects to the PostgreSQL object-relational DB, making it a spatial BD for use in Geographic Information System. It is published under the General Public License of the GNU Project (PostGIS, 2012).

PostGIS version 1.5.2-3 was applied as a link between the map server and the BD server, as it adds geographic object support to the PostgreSQL BD and implements spatial extensions based on the specifications of the Open Geospatial Consortium (OGC).

ExtJS is a JavaScript library for the development of interactive web applications using technologies such as AJAX, DHTML, and DOM. Originally built as an extension of the YUI library, it can now be used as an extension for the JQuery and Prototype libraries. Since version 1.1 it can be run as a standalone application (Zonageo, 2012).

Linares, J. A. M., Gámez, M. R., \& Pérez, A. V. (2019). Computer application for studies of potential renewable energy sources. International Research Journal of Management, IT and Social Sciences, 6(6), 37-42. https://doi.org/10.21744/irjmis.v6n6.754 
The JavaScript library called ExtJS version 3.4.0, is applied with the aim of improving user interaction, as it offers the ability to provide components with advanced functionalities and simple implementation. It's about them being easy to use and intuitive.

The library is applied GeoExt, which is a tool used for building web map applications based on JavaScript (Zonageo, 2012). In this case, GeoExt version 1.1 is used, which a tool is built from the robust OpenLayers library and the rich graphic components of ExtJS. It has components for GIS applications, allowing you to create powerful JavaScript-based map websites.

For its part, OpenLayers is a JavaScript library (provided from a modified BSD license) to display maps and other geographic data in a Web browser. It includes an API to build rich applications similar to GoogleMaps (Google, 2005). The library includes components of the Rico and Prototype library (Zonageo, 2012). Specifically for the project, OpenLayers version 2.12 is used to facilitate the handling of client-side maps.

In figure 1, the relationship scheme of the different technologies used for the development of SIGFRE can be appreciated.

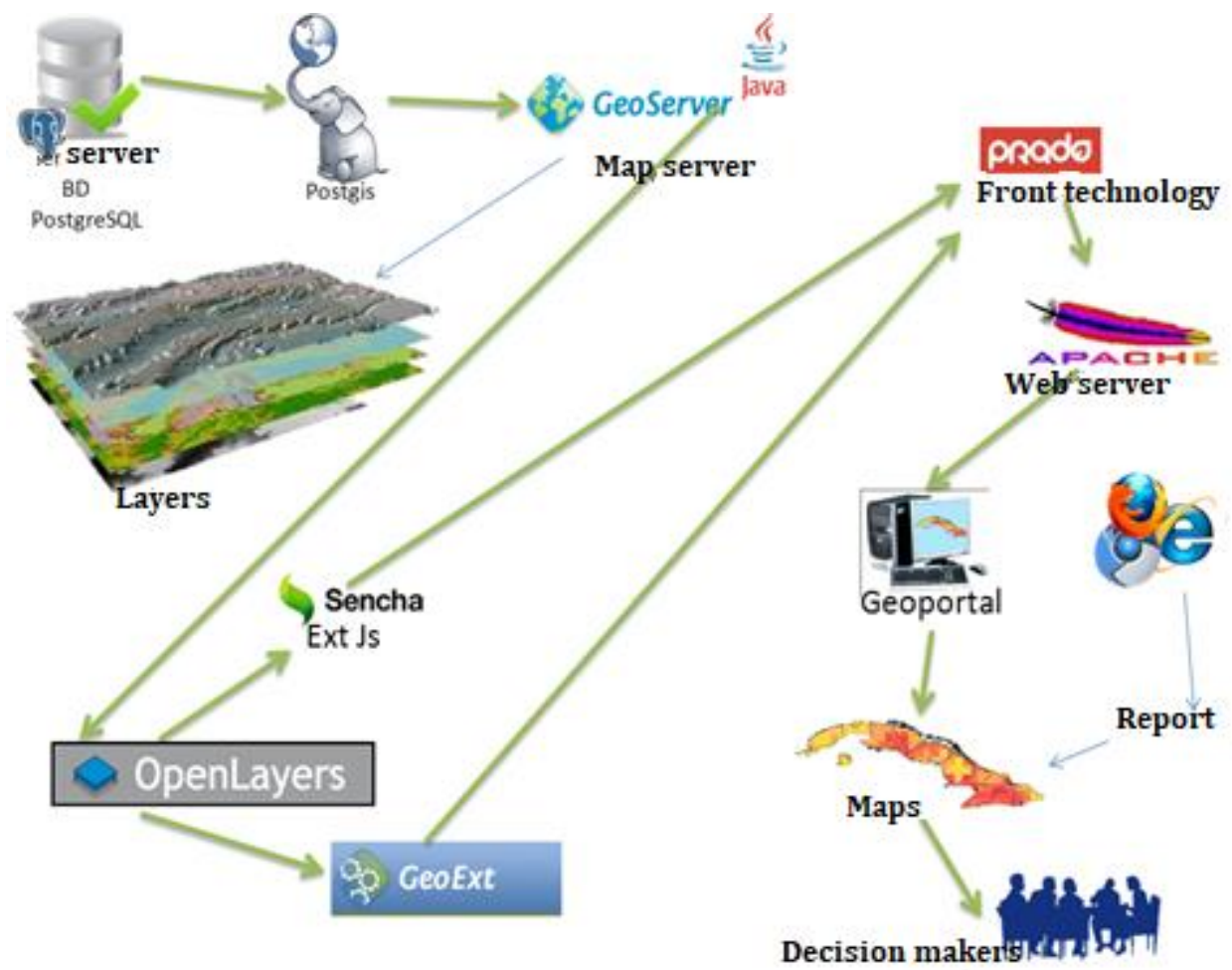

Figure 1. Diagram of the relationship between the different technologies used for the development of SIGFRE

\section{Application presentation}

The application is prepared to be operated by users in an intuitive, simple and friendly way, that is, without having specialized computer skills, consultation actions can be carried out and in some cases updates in the different modules for which it is located conceived the system.

The opening of the system has been conceived through a web page with various information of the FRE and through the hyperlinks of the menu, the different sub-modules related to the information of the registry are accessed.

In figure 2, shows the sub-module of the solar potential. In this case, if you want to know the characteristics of the solar radiation of a site, just by clicking on the location on the map, the information is shown by months and the annual average of the potential itself. 


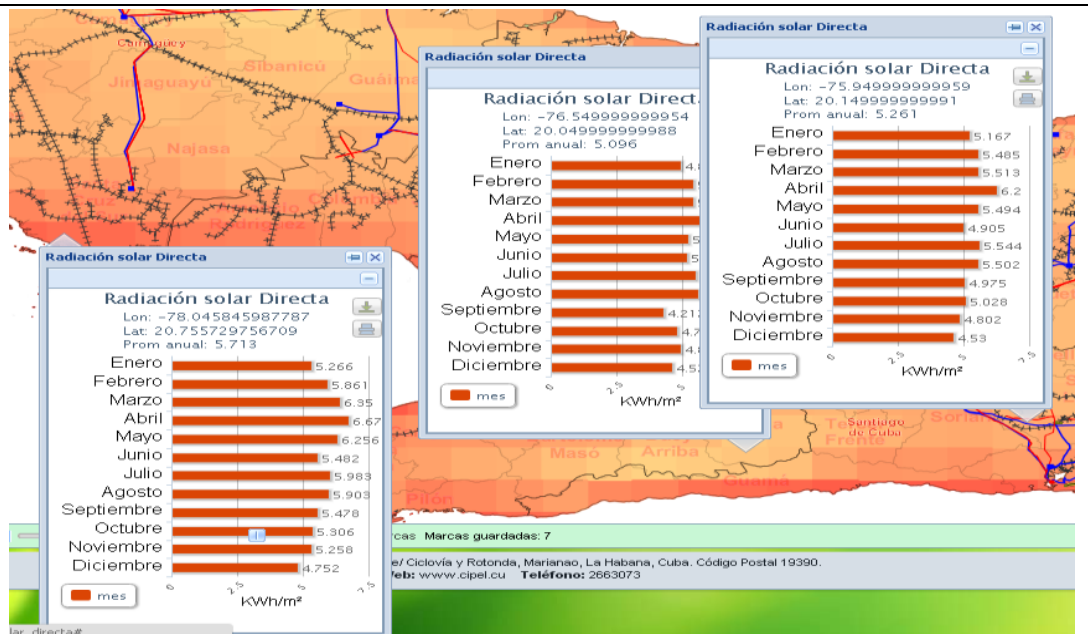

Figure 2. Solar potential seconds after the user asked the SIGFRE

The system has potential to be used by users identified in the different levels of the political and administrative system of the country, being able to help in the process of territorial energy planning in the short, medium and long term, contributing to developing the use of renewable sources and the development of the territories.

\section{Conclusion}

SIGFRE is able to offer reliable, integrated and timely georeferenced information on inventories and potentials of the FRE, making available to users a useful tool with which to interact to ensure the adequate use of the energy resources that exist at the level of the localities, with the capacity to fill an informational vacuum that integrates and facilitates access to multiple sustainable energy applications for the territories.

\section{Conflict of interest statement}

The authors declared that they have no competing interest.

\section{Statement of authorship}

The authors have a responsibility for the conception and design of the study. The authors have approved the final article.

\section{Acknowledgments}

We thank the editor of IRJMIS for their valuable time, support and advice.

Linares, J. A. M., Gámez, M. R., \& Pérez, A. V. (2019). Computer application for studies of potential renewable energy sources. International Research Journal of Management, IT and Social Sciences, 6(6), 37-42. 


\section{References}

Cedeno, M. L. D., Arteaga, M. G. D., Perez, A. V., \& Arteaga, M. L. D. (2017). Regulatory framework for renewable energy sources in Ecuador case study province of Manabi. International Journal of Social Sciences and Humanities, 1(2), 29-42. https://doi.org/10.29332/ijssh.v1n2.33

Chilán, J. C. H., Torres, S. G. P., Machuca, B. I. F., Cordova, A. J. T., Pérez, C. A. M., \& Gamez, M. R. (2018). Social impact of renewable energy sources in the province of Loja. International Journal of Physical Sciences and Engineering, 2(1), 13-25. https://doi.org/10.29332/ijpse.v2n1.79

Chuvieco, E., Pons, X., Conesa, C., Santos, J., Gutiérrez, J., Salado, M., Martín, M., Riva, J, Ojeda, J., Prados, M. (2005). Are Information Technologies Geographic (TIG) part of the core of Geography? Bulletin of the AGEN 40, p. 35-55. Meadow.

Available

from: http://www.ecured.cu/index.php/PRADO_\%28Aplicaci\%C3\%B3n_web\%29.

Geoserver (2012). www.zonageo.com.ar. www.zonageo.com.ar/node/1.

Google Maps (2005). Google. What is Available from: http://www.googlemaps.es/?page 3.

Pérez, A. V., Castillo, G. A. L., Alava, L. A. C., \& Chilan, J. C. H. (2016). The regulatory framework for renewable energy sources. International Research Journal of Management, IT and Social Sciences, 3(11), 8-21.

PostGIS (2012). www.zonageo.com.ar. Available from: www.zonageo.com.ar/node/1.

Ramos, JLM, Pérez, AV, Gámez, MR, \& Zambrano, RVH (2018). Renewable energy sources on the change of energy matrix in Manabí province. International Research Journal of Engineering, IT \& Scientific Research , 4 (4), 1729. https://doi.org/10.21744/irjeis.v4n4.255

Rodríguez M., Ramos, R., Alonso, (1998). Information system for energy planning with renewable energy sources. CD-Congress, SENESE X, 1998. Punta arenas, Chile.

Rodríguez, M., Marques, S., Chery, E., Cisnero, I. Morell, M. (2005). Use of the Geographic Information System (GIS) as a tool in decision-making in the rural electrification program. Scientific magazine of renewable energies. ISBN: 959-250-2005. (ISSN: 1028 6004).

Rodríguez, M., Marquez, S. (1999). INFOSOLAR: Informative Graphic System for rural electrification. Sept. 99. Energy and Development. E\&D, 1999. 15 (Bolivia).

Rodríguez, M., Núñez, A., Ramos, R., Marquez, S. (2000). Information System for Energy Planning with Renewable Sources. Proceeding Eurosun 202 Page 131.

Shiota, A. Cisnero, I., Rodríguez, M., Torres, A., Vives, A., Jiménez, O., Gustavo, M., Ramos, R., Marquez, S., Camejo, E., Ferrer, M. Guide of recommendations for the use of Renewable Energies in Rural Electrification. Report files of the Centrode Investigaciones de Energía Solar (CIES) and the Center for Priority Program and Project Management (GEPROP) of the Ministry of Science, Technology and Environment (CITMA) of Cuba. 2002.

SIG, (2019), https://www.arcgis.com/home/webmap.

Stiglitz, J., (2012). The price of inequality. Private copy for educational purposes, ISBN: 9788430601349.

Zonageo (2012). www.zonageo.com.ar. Available from: www.zonageo.com.ar/node/1. 